\title{
Screening of variable importance for optimizing electrodialytic remediation of heavy metals from polluted harbour sediments
}

\author{
Pedersen, Kristine B.; Lejon, Tore; Ottosen, Lisbeth M.; Jensen, Pernille Erland
}

Published in:

Environmental Technology (United Kingdom)

Link to article, DOI:

$10.1080 / 09593330.2015 .1028470$

Publication date:

2015

Document Version

Peer reviewed version

Link back to DTU Orbit

Citation (APA):

Pedersen, K. B., Lejon, T., Ottosen, L. M., \& Jensen, P. E. (2015). Screening of variable importance for optimizing electrodialytic remediation of heavy metals from polluted harbour sediments. Environmental Technology (United Kingdom), 36(18), 2364-2373. https://doi.org/10.1080/09593330.2015.1028470

\section{General rights}

Copyright and moral rights for the publications made accessible in the public portal are retained by the authors and/or other copyright owners and it is a condition of accessing publications that users recognise and abide by the legal requirements associated with these rights.

- Users may download and print one copy of any publication from the public portal for the purpose of private study or research.

- You may not further distribute the material or use it for any profit-making activity or commercial gain

- You may freely distribute the URL identifying the publication in the public portal 


\section{Screening of Variable Importance for Optimsing Electrodialytic Remediation of Heavy Metals from Polluted Harbour Sediments}

Kristine B. Pedersen ${ }^{\mathrm{a}}$, Tore Lejon ${ }^{*}$, Lisbeth M. Ottosen ${ }^{\mathrm{b}}$ and Pernille E. Jensen $^{\mathrm{b}}$

${ }^{a}$ Department of Chemistry, University of Tromsø, The Arctic University of Norway, Postbox 6050 Langnes, N-9037 Tromsø, Norway.

${ }^{b}$ Arctic Technology Centre, Department of Civil Engineering, Technical University of Denmark, Building 118, 2800 Lyngby, Denmark

*Corresponding author: e-mail tore.lejon@uit.no; tel. +47 776 44736; fax. +47 776 44765

Short title: Variable Importance for Optimsing Electrodialytic Remediation

\section{Acknowledgements}

Hammerfest municipality is acknowledged for providing a boat for sampling of sediments in Hammerfest.

\section{Funding}

The Northern Environmental Waste Management (EWMA) project, which is funded by the Research Council of Norway through NORDSATSNING (grant number 195160) and Eni Norge AS, provided funding for the project.

\section{Disclosure statement}

T. Lejon is the CEO of ARTTsynthesis, although this company has no financial interest in the research presented in this paper, which is financed fully by the Research Council of Norway.

\section{Word count}

5,097 words 


\title{
Screening of Variable Importance for Optimsing Electrodialytic Remediation of Heavy Metals from Polluted Harbour Sediments
}

\begin{abstract}
Using multivariate design and modelling, optimal conditions for electrodialytic remediation (EDR) of heavy metals were determined for polluted harbour sediments from Hammerfest harbour located in the geographic Arctic region of Norway. The comparative importance of the variables; current density, remediation time, light/no light, the liquid-solid ratio and stirring rate of the sediment suspension were determined in 15 laboratory scale EDR experiments by projection to latent structures (PLS). The relation between the $\mathrm{X}$ matrix (experimental variables) and the $\mathrm{Y}$ matrix (removal efficiencies) was computed and variable importance in the projection was used to assess the influence of the experimental variables. Current density and remediation time proved to have the highest influence on the remediation of the heavy metals $\mathrm{Cr}, \mathrm{Cu}, \mathrm{Ni}, \mathrm{Pb}$ and $\mathrm{Zn}$ in the studied experimental domain. In addition it was shown that excluding the acidification time improved the PLS model, indicating the importance of applying a limited experimental domain that covers the removal phases of each heavy metal in the specific sediment. Based on PLS modelling the optimal conditions for remediating the Hammerfest sediment was determined; operating in the experimental domain of $0.5-0.8 \mathrm{~mA} / \mathrm{cm}^{2}$ and a remediation time after acidification of 450-570 hours met acceptable levels according to Norwegian sediment quality guidelines.
\end{abstract}

Keywords: Chemometrics, Projections onto Latent Structures (PLS), electrodialytic remediation, heavy metals, harbour sediments 


\section{Introduction}

Large amounts of sediments are annually dredged worldwide due to harbour development and/or to meet the demands of governmental acts to improve the aquatic environment of harbours. The most common ways of dealing with dredged polluted sediments are disposal (on land/at sea) and to a lesser degree solidification and stabilisation (STSO) in which the polluted sediments are incorporated in constructions, e.g. harbour foundations. Development of treatment strategies for the dredged polluted sediments has been limited. Due to the increasing focus on moving towards more sustainable societies, ideally zero-waste societies, along with the considerations of minimising the pollution legacy for future generations, emphasis on developing methods to remediate contaminated sediments to levels assessed as non-polluted hence increasing the potential recycling opportunities may be expected in the future.

This issue is increasingly noticeable also in the Arctic region e.g. in Hammerfest in the north of Norway. The harbour has been identified as one of 17 harbours of highest priority for remedial actions by the Norwegian national action plan for polluted seabed [1]. In Hammerfest the harbour sediment pollution originates from several sources over the past 50-60 years and has a complex composition of various pollutants, including heavy metals, PAHs, PCBs and TBT.

Even though electrodialytic remediation (EDR) has proven a liable method for removing heavy metals from polluted sediments the method has not been systematically studied using chemometrics. The objective of the study was therefore to employ statistical experimental design in order to identify the relative importance of experimental variables and to find optimal settings for achieving satisfactory remediation. 


\section{Multivariate design and modelling}

Regardless of experimental method employed, it is of utmost importance that experiments are conducted in such a manner that changes in the experimental setup will be reflected in the result. Though this may sound logical, it is not always the case in practise and one often encounters studies claiming to result in optimal conditions without any real proof of it being the case. A typical example is when conducting the “optimization” by changing one variable at a time (OVAT) by first finding the best outcome for one experimental variable followed by keeping this variable constant while changing the next variable(s). This will lead to false optima if the variables are correlated, which is often the case, e.g. time - concentration or time - temperature. The solution to this problem is to conduct experiments in such a way that optimum settings for independent as well as correlated variables are found. An efficient way of ensuring this is by employing statistical experimental design [2].

A complete two-level factorial design contains all possible combinations of the settings of the factors and a factorial design with $\mathrm{k}$-factors hence contains $2^{\mathrm{k}}$ experiments, resulting in all variables and all variable interactions being modelled. A major advantage of this type of design is that the results may be calculated without the use of expensive software. A fractional factorial design is constructed as a fraction of a complete factorial design, thus containing less information as some variables will be confounded with other variables. The fraction is a $1 / 2^{\mathrm{p}}$ fraction of a complete factorial design giving a total of $2^{\mathrm{k}-\mathrm{p}}$ experimental runs [2]. Experiments are selected to cover a maximum variation over the experimental space. Even though a fractional design contains less information, due to confounding, it is possible to construct the design so that main effects and two-variable effects are only confounded with higher order 
interaction effects. Since higher order interaction effects are assumed to be negligible, the fractional designs can be used to obtain good estimates of the true main effects and the true two-variable interaction effects [2]. For most studies the identification and setting/tuning of the most important variables will be sufficient for obtaining satisfactory results but there are methods of extracting more information from the data, e.g. by employing the experimental variables as input in Projections to Latent Structures (PLS) analysis.

PLS is a multivariate method based on projections and is used for modelling quantitative relationships between a descriptor matrix, $\mathrm{X}$ and a response matrix, $\mathrm{Y}$. Object points in both the $\mathrm{X}$ and $\mathrm{Y}$ spaces are projected down to a PLS component. For each PLS dimension the scores of the Y-block has a maximum correlation to the scores of the X-block. New PLS components are introduced until all the systematic variation in the Y-block has been described and only noise remains [2-5]. Advantages of PLS are that it can cope with collinearity between variables, noise in both the $\mathrm{X}$ and $\mathrm{Y}$ matrices and that moderate amounts of missing data is tolerated.

The fraction of the variation in the Y matrix explained by the model is expressed in the term R2Y and the predictive power, Q2, is an estimate of the reliability/stability of the model calculated by cross-validation. Ideally, these values should be as high as possible and of the same magnitude, which would indicate that the model is valid within the domain investigated.

The results from the calculations can be presented in different ways, e.g. in Variable Importance in the Projection (VIP) plots. In this manner, the importance of each parameter in the model (the experimental variables in the $\mathrm{X}$ matrix) can be visualized with respect to its correlation to the responses (e.g. the remediation levels in the Y matrix). VIP plots reflect the relative importance of the model parameters and 
parameters with VIP values larger than 1 are considered relevant for explaining the responses (remediation levels). However, in order to determine if the setting of the experimental variable should be high or low for optimal results, response surfaces should be calculated.

\section{Electrodialytic remediation}

EDR of heavy metals from solid waste materials was developed at the Technical University of Denmark in the early 1990s. The method has since then been used for remediation of harbour sediments achieving removal efficiencies up to $99 \%$ of the original heavy metal content and/or to levels below national threshold values and recommended values from OSPAR [6-13]. EDR is based on the principles of electrokinetic remediation (EKR), in which an electric field is applied, subsequently mobilising charged particles in the solid waste. A low level current (in the order of $\mathrm{mA} / \mathrm{cm}^{2}$ of the cross sectional area between the electrodes) is applied and the fluid in the polluted material acts as the conductive medium. Transport processes are dominated by electromigration, i.e. the transport of ions and ionic complexes in the pore fluid of the polluted material [14-16].

The electric field initiates electrolysis reactions at the electrode, producing $\mathrm{H}^{+}$ ions at the anode and $\mathrm{OH}^{-}$ions at the cathode. Since the effective ionic mobility of $\mathrm{H}^{+}$is higher than that of $\mathrm{OH}^{-}$, an acidic front in the polluted material prevails; subsequently desorbing and mobilising heavy metals under the influence of the applied electric field [14-16].

EDR controls the formation and progress of the acidic and alkaline fronts by applying ion exchange membranes, separating the polluted material from the electrodes and circulating electrolytes, thus controlling the transport of ions between the polluted 
material and electrolytes. Acidification of the polluted material takes place due to water splitting at the anion exchange membrane placed adjacent to the anode [17].

Based on a kinetics study on the electrodialytic removal of $\mathrm{Al}, \mathrm{Fe}, \mathrm{Ca}, \mathrm{K}, \mathrm{Mg}, \mathrm{Mn}$ and $\mathrm{Pb}$ from an industrially polluted soil[18]; the removal of a given metal during EDR can be divided into four phases:

(1) Lag phase; the $\mathrm{pH}$ decreases to the threshold value at which desorption of the given metal is initiated (acidification). During this phase there is a limited removal of the given metal.

(2) Fast metal removal phase; rapid dissolution/desorption of metal in the available fraction of the sediment.

(3) Slow metal removal phase; continuous dissolution/desorption of metal in the lesser available fractions of the sediment which could also include dissolution of stable soil minerals.

(4) Stationary phase; removal of the metal ends.

The time and metal removal rate of each phase in EDR depends on how the metal is bound in the sediment, sediment properties and the chosen experimental domain. A high buffer capacity will for instance delay the process [16] by prolonging the lag phases of the metals that are not predominantly bound to carbonates. An EDR study of sediments with different properties revealed variation in the removal efficiencies within the same experimental domain [12]. Other EDR studies showed that current density, remediation time and to a lesser degree the L/S of the experimental sediment suspension significantly influenced the removal efficiencies [6-9]. Since the experimental domain influences the $\mathrm{pH}$ development in the sediment it also influences the different phases of the EDR; e.g. the lower the operating $\mathrm{pH}$ the higher propensity of dissolving more of 
the stable soil minerals hence prolonging the slow metal removal phase prior to obtaining stationary conditions.

Several EKR and EDR studies of polluted sediments have shown limited removal of targeted heavy metals applying the traditional stationary set-up with removal efficiencies generally below $20 \%$ with a few exceptions of up to $40 \%$ [12, 19-22]. Removal efficiencies of up to 70\% have been reported by applying desorbing agents as an enhancement technique [21]. Another technique for enhancing removal efficiency is to apply a set-up in which the sediment in suspension is continuously stirred, resulting in fast removal of up to $99 \% \mathrm{Cd}, 86 \% \mathrm{Cu}, 95 \% \mathrm{~Pb}$ and $86 \% \mathrm{Zn}$ in the sediment $[7,8$, 13]. Applying desorption agents in the stirred set-up [12] did not increase the removal efficiencies of $\mathrm{Cd}, \mathrm{Pb}$ and $\mathrm{Zn}$ indicating that the stirred set-up has a higher comparative importance for the removal efficiencies. In addition lower interferences of the system were reported in the stirred set-up [10, 12].

\section{Methods and Materials}

\section{Experimental design}

In the first set of experiments the influence of the continuous variables current density, remediation time, $L / S$ ratio and stirring rate of the sediment suspension; and the discrete variables light/no light and suspension liquid (tap water/distilled water) were determined. Undertaking a complete two-level factorial design would entail conducting $2^{6}(64)$ experiments. By assuming that the interaction effects between three to six factors are negligible, the amount of experiments can be reduced to a $2^{6-3}$ fractional factorial design consisting of 8 experiments (1-8) equivalent to a complete $2^{3}$ fractional design. In addition, 2 experiments with light and 2 experiments without light were conducted at average values of the other variables (9-12). 
Three more experiments (13-15) were conducted to assess the influence of current density and remediation time after acidification $(\mathrm{pH}=4)$. The experiments fit with a $2^{2-1}$ fractional factorial design with one centre experiment.

The experimental settings are presented in table 1.

Table 1

\section{EDR Experiments}

Sediments from Hammerfest harbour (coordinates 70.39.87N and 23.41.31E) were sampled in the fall of 2010 using a Van Veen grab. The sediments were sampled from the top $10 \mathrm{~cm}$ of the seabed at a depth of approximately $12 \mathrm{~m}$. The sediments were kept cool during transport to the laboratory where they were stored in a freezer until used in the experiments.

The electrodialytic cell was manufactured from Plexiglas and consisted of 3 compartments; the centre compartment contained the polluted sediments in suspension and electrolyte liquids were circulated in the two adjoining compartments. The length of the centre compartment was $10 \mathrm{~cm}$, the length of each electrolyte compartment was 3.5 $\mathrm{cm}$ and all three compartments had an inner diameter of $8 \mathrm{~cm}$. Ion exchange membranes from Ionics (anion exchange membrane 204 SZRA B02249C and cation exchange membrane CR67 HUY N12116B) separated the electrolyte compartments from the polluted sediment compartment. $\mathrm{NaNO}_{3}(0.01 \mathrm{M})$ was used as electrolyte liquids and was continuously adjusted to $\mathrm{pH} 2$ by $\mathrm{HNO}_{3}(5 \mathrm{M})$. The electrolytes (300 ml) were circulated via Ismatec reglo pump with a flow rate of $10 \mathrm{ml} / \mathrm{min}$. Platinum coated titanium electrodes were used in each electrolyte compartment and a power supply (Hewlett Packard E3612A) maintained a constant DC current. The sediment suspension was stirred by a CAT R14 motor with a stirrer consisting of plastic flaps $(4 \mathrm{~cm} \mathrm{x} 0.5 \mathrm{~cm})$ fastened to a glass rod. 
After the EDR experiments sediments were filtered through a Whatman CAT 1113-320 filter $(32.0 \mathrm{~cm})$ and the metal concentrations in both the suspension liquid and solids were measured. The stirrer, membranes and electrodes were soaked in $\mathrm{HNO}_{3}$ (5M) overnight and the heavy metal concentrations in the soaking liquids as well as the electrolyte liquids were measured.

\section{Sediment analysis}

Major elements and heavy metal concentrations (Al, Ba, Ca, Fe, K, Mg, Mn, $\mathrm{Na}, \mathrm{V}, \mathrm{Cr}$, $\mathrm{Cu}, \mathrm{Ni}, \mathrm{Pb}, \mathrm{Zn}$ ) were measured based on digestion (Norwegian standard NS4770). Sediment dried at $105^{\circ} \mathrm{C}(1.0 \mathrm{~g})$ and $\mathrm{HNO}_{3}(9 \mathrm{M}, 20 \mathrm{~mL})$ were autoclaved $(200 \mathrm{kPa}$, $120^{\circ} \mathrm{C}, 30$ minutes). Solid particles were subsequently removed by vacuum filtration through a $0.45 \mu \mathrm{m}$ filter and the liquid was diluted to $100 \mathrm{~mL}$. Metal concentrations in the liquid were measured by Inductively Coupled Plasma (ICP-OES) and are given as mg metal per kg dry matter.

Sequential extraction was made in four steps based on the improvement of the three-step method [23] described by Standards, Measurements and Testing Program of the European Union. Air-dried sediment (0.5g) was treated in four steps: extraction with acetic acid (0.11M, 20mL, pH3) for 16 hours; extraction with hydroxylammonium chloride $(0.1 \mathrm{M}, 20 \mathrm{~mL}$; $\mathrm{pH} 2)$ for 16 hours; extraction with hydrogen peroxide (8.8M, $5 \mathrm{~mL}$ ) for 1 hour, followed by extraction at $85^{\circ} \mathrm{C}$ for 1 hour, followed by evaporation of liquid at $85^{\circ} \mathrm{C}$, subsequently the cooled solid fraction was extracted with ammonium acetate (1M, 25mL, pH2) for 16h; digestion as described above.

\section{Multivariate analysis}

In this study SimcaP11 software was used for PLS modelling based on the experiments in table 1 . The $\mathrm{X}$ matrix consisted of the 6 experimental variables and the $\mathrm{Y}$ matrix consisted of the removal efficiencies, calculated as the final concentrations compared to 
the initial concentrations in the sediment (\%). In order to include the discrete variables in the modelling, the two different conditions were arbitrarily assigned the value 1 or -1 . VIP Plots were used to assess the variable importance for the models computed. Since VIP plots are based on relative values, comparison between different models is possible. However, the plots do not convey the numerical influence of variables, so in order to establish whether a given variable has a positive/negative influence on the model, contour plots were used.

Preliminary PLS modelling showed that experiment 11 deviated from the remaining experiments for all metals/heavy metals, although not as a statistical outlier (high voltage indicating disturbances to the system was registered and the final $\mathrm{pH}$ was high compared to the other three centre experiments) and the experiment was excluded from further modelling.

\section{Results and discussion}

\section{Screening of variable importance for the remediation}

Prior to PLS modelling of the results, a one factor variance analysis of all the experiments was undertaken to determine whether there was a significant difference between the initial and final concentrations of the metals/heavy metals in the sediments.

The influence of EDR was apparent for $\mathrm{Ba}, \mathrm{Ca}, \mathrm{K}, \mathrm{Mg}, \mathrm{Mn}, \mathrm{Na}, \mathrm{Cr}, \mathrm{Cu}, \mathrm{Ni}, \mathrm{Pb}$ and $\mathrm{Zn}$, where a significant difference was registered while the F values were below the critical value (3.99) for Al, Fe and Ni, indicating similar levels of initial and final concentrations. For these three elements the experimental domain may have covered a large part of the initial lag phase of EDR with limited metal removal. Since part of the experimental domain could still cover the removal phase(s) of these three elements, it was decided to include them in the PLS modelling. 
The following PLS models were calculated:

Model 1a: Based on design 1 in table 1 (11 experiments)

Model 1b: Based on design 1 in table 1; substituting the variable time with time after acidification

Model 2: Based on design 2 in table 1 (3 experiments)

Model 1a had a good correlation factor, R2Y of 0.74 (figure 1). The predictive power, Q2, of the model should ideally have a similar value; however, for model 1 the Q2 value of 0.045 is very low, indicating that the model is not stable within the experimental domain.

Figure 1

In the VIP plot of model 1a, the relative importance of experimental variables are in the order current density (1.80)> time (0.96) suspension liquid (0.93)>stirring rate $(0.70)>L / S(0.65)>$ light $(0.29)$. The low Q2 value of the model could indicate that the studied experimental domain does not cover the removal phase(s) of the metals/heavy metals in the model, in which case the experimental domain should be adjusted.

Experimental observations of varying acidification time (not necessarily related to the variation in the other experimental variables) indicated that applying the total remediation time as a variable could result in deviations in the PLS modelling. This would especially be the case when the acidification time constitutes a high fraction of the total remediation time. Based on these considerations a new model was calculated (model 1b), in which the 'total remediation time' was substituted by the variable 'time after acidification' $(\mathrm{pH}<4)$, based on the same 11 experiments as in model 1a. Adjusting the time variable leads to a skewed fractional factorial design, none the less the results have an indicative value. 
The correlation factor, R2Y of 0.75 , was similar to the correlation factor of model $1 \mathrm{a}$. The predictive power of the model increased manifold in comparison with that of model 1a and had a Q2 value of 0.44 (figure 1). In model 1b the VIP plot (figure 2) deviates from model 1a with a variable importance order of time after acidification (1.63) $>$ current density (1.34)>>suspension liquid (0.78) stirring rate $(0.67) \sim L / S(0.64)>$ light (0.26). Time after acidification and current density hence influence the model to a larger extent than the other variables. The difference in the VIP plots between the two models further accentuates the importance of time after acidification rather than the total time of the remediation in the modelling, most probably related to larger parts of the initial EDR lag phases of the different metals being excluded from the model. Previous EDR studies of harbour sediments have focused on the total remediation time [6-12, 24]; acknowledging the influence of carbonate content and hence acidification time on EDR [12], the studies were however not based on chemometric modelling. The findings of the PLS models 1a and 1b confirm the development of the different EDR phases [18] as a function of time. It is also worth noting that the earlier EDR studies of sediments have focused on the influence of experimental settings on each metal individually, rather than including several metals in the same analysis, as made possible by the PLS calculations for models $1 \mathrm{a}$ and $1 \mathrm{~b}$.

To test whether the model correlation and predictability could be further improved by applying time after acidification rather than the total remediation time in the experimental design, model 2 was computed based on three new experiments (design 2, table 1). Due to the findings in model 1a and 1b, the experimental design only included the two most important variables - current density and time after acidification; and in order to focus on the fast removal phases of EDR the time range was narrowed. 
The correlation factor R2Y, was 0.82 and the prediction power, Q2 was 0.65 (figure 1), a vast improvement compared to model 1a. A VIP plot (not shown) revealed equal variable importance in the two experimental variables, indicating that time after acidification and current density were equally important for the metal removal efficiencies in the three experiments.

Including all the metals in the models, as done above, gives a general overview of the data, i.e. how well the experimental domain has been defined and also the general trends in variable importance. Since the time ranges of the metal removal phases vary among the metals, the chosen experimental domain may not be simultaneously ideal for all metals.

To assess any differences in model trends and variable importance for the different metals, new models for each metal were computed. The correlation factors and predictive power of each metal in the three models vary (figure 1) and with the exception of $\mathrm{Ca}, \mathrm{Mg}, \mathrm{Na}$ and $\mathrm{Zn}$, the models for each metal improves from model 1a to model 1b to model 2 (figure 1). A reason for the poorer models for $\mathrm{Ca}, \mathrm{Mg}, \mathrm{Na}$ and $\mathrm{Zn}$ could be the narrow experimental time range (when scrutinising the data it is found that the concentration levels for each of these metals are not affected by the experimental settings). Since these metals appear to be in the stationary phase of the EDR it is justifiable to exclude them from model 2. Modelling the remaining metals in one model vastly improves the model with a correlation factor of 0.97 and a predictive power of 0.94 .

Figure 2

Since the model correlation factors and predictive power varies from metal to metal, one may also expect a variation in the relative importance of variables depending on the metal. This trend is exemplified by the variation in the variable importance of the 
different metals in model 1b (figure 2). For illustrative purposes the metals have been grouped into: mobile metals naturally occurring in sediments (Ca, $\mathrm{K}, \mathrm{Mg}, \mathrm{Na}$ ); less mobile metals naturally occurring in sediments (Al, Ba, Fe, Mn, V) and contaminants (Cr, $\mathrm{Cu}, \mathrm{Ni}, \mathrm{Pb}, \mathrm{Zn})$.

As illustrated in figure $2 b$ the variables that influence the removal of the mobile metals in the sediment are current density, time after acidification and suspension liquid. Contour plots of the metals (not shown) reveal that applying distilled water rather than tap water increases the removal efficiencies, indicating that distilled water dissolves more salts, making especially $\mathrm{Ca}, \mathrm{Mg}$ and $\mathrm{Na}$ more available for extraction.

For the naturally occurring metals in the sediment matrix, $\mathrm{Al}, \mathrm{Ba}, \mathrm{Fe}$ and $\mathrm{Mn}$ the general trend is that time after acidification and current density have the highest relative importance for the removal efficiencies. For $\mathrm{V}$ it appears that the stirring rate rather than the current density influences the removal efficiency, indicating that a relatively larger part of $\mathrm{V}$ is present in the exchangeable fraction of the sediment compared to the other metals. This is supported by the estimation of the exchangeable fractions of the different elements by sequential extraction (figure 3).

For the contaminants $\mathrm{Cr}, \mathrm{Cu}, \mathrm{Ni}, \mathrm{Pb}$ and $\mathrm{Zn}$; figure $2 \mathrm{~d}$ illustrates that current density and time after acidification have higher comparative importance for the remediation efficiencies than the other variables. Previous EDR studies of sediments have applied OVAT designs with up to 3 variables and have hence not included possible interactions between variables. Although direct comparison of variable importance on EDR was not the main objectives of the studies, some general trends can be retrieved. In general, remediation time and current density had the highest influence on removal efficiencies of the studied heavy metals ( $\mathrm{Cd}, \mathrm{Cu}, \mathrm{Pb}$ and $\mathrm{Zn})[7,8,10]$. However, in one of the studies, L/S was found to be more significant than current density for $\mathrm{Cu}$ and $\mathrm{Zn}$ [8], 
while another study found that stirring rate was more significant for the removal of $\mathrm{Cu}$ and $\mathrm{Pb}$ than current density [10]; the remediation time was constant in both studies. In the present study current density and time after acidification were consistently found to be more important than the other variables. The difference in the results may be due to the different experimental domains and sediments studied and emphasise that removal of each heavy metal from the same sediment may be different depending on how they are bound in the sediment and to a lesser degree, the experimental settings.

\section{EDR effect on the sediment matrix}

Prior to proceeding with optimisation for the EDR process, an assessment of the remediation effect on the sediment matrix was performed. The removal efficiency of each metal was compared to the distribution of the metal in the different fractions of the sediment (figure 3); exchangeable, reducible, oxidisable and residual estimated by sequential extraction.

Figure 3

For the elements $\mathrm{Al}, \mathrm{Ca}, \mathrm{Fe}, \mathrm{Mg}, \mathrm{Mn}, \mathrm{Na}$ the highest levels of removal are similar to the amounts found in the exchangeable fraction of the sediment. These findings are in line with the predictive powers of the individual modelling of Model 1b which indicate that after acidification, these metals are removed at a rate consistent to the fast metal removal phase of the exchangeable fractions.

The individual modelling of $\mathrm{Ba}, \mathrm{K}$ and $\mathrm{V}$ in Model 2 (figure 1) resulted in poorer predictive powers indicating that the experimental domain covered different phases of the metal removal. This is further supported by the highest levels of metal removal being equivalent to residual fraction levels of the sediment indicating the metal removal at this stage could be either in the slow metal removal or stationary phase. 
The removal efficiencies of $\mathrm{Cr}$ and $\mathrm{Ni}$ are lower than the amounts found in the exchangeable fractions, which could be due to the acid exchangeable fractions not being completely dissolved at the $\mathrm{pH}$ levels of the experiments. The removal efficiency of $\mathrm{Pb}$ is equivalent to the exchangeable fraction and along with results of Model 2 this suggests that within the experimental domain, $\mathrm{Pb}$ was in the fast metal removal phase of EDR. $\mathrm{Cu}$ and $\mathrm{Zn}$ were also removed from the oxidisable and reducible fractions of the sediment, respectively. The predictive powers of these two elements were however good, so it is not possible to assess whether the two metals have moved into the slower metal removal phases with minor influences on the model; or whether they remain in the fast removal phase within the experimental domain. In a previous study, the heavy metal removal from the oxidisable fractions was attributed to the stirred set-up which enhanced the oxidation of the sediment, thus releasing heavy metals bound in these fractions [9]. Whether the stirring rate prolongs the fast removal phase has however not been investigated.

The above analysis shows that comparison of removal efficiencies in relation to sediment fraction distribution and the PLS model(s) can give indications of which EDR phases each metal undergoes over the studied experimental domain.

\section{Application of model for optimisation of remediation}

The maximum quantitative removal of contaminants in the applied experimental domain is illustrated in figure 4 and is compared to two sets of background levels in sediments as defined by the Norwegian EPA and OSPAR. The initial concentrations of $\mathrm{Cr}$ and $\mathrm{Ni}$ are low and although elevated compared to the background levels of OSPAR, are not high enough to be of concern. The concentrations of the heavy metals targeted in this study, $\mathrm{Cu}, \mathrm{Pb}$ and $\mathrm{Zn}$, significantly exceed the Norwegian sediment quality criteria. Figure 4 
The removal efficiencies of $\mathrm{Cu}, \mathrm{Pb}$ and $\mathrm{Zn}$ are up to 70\%, 79\% and 69\%, respectively, in the applied experimental domain and meet the background levels of the Norwegian EPA. The removal efficiencies of $\mathrm{Cu}$ and $\mathrm{Zn}$ do not reach the background values of OSPAR and if these are to be met, the experimental domain should be expanded.

The sediment-specific removal efficiencies as a function of the experimental variables can be visualised in contour plots. The plots for $\mathrm{Cu}, \mathrm{Pb}$ and $\mathrm{Zn}$, from model $\mathrm{1b}$ calculations, are shown in figure 5. Based on the screening of variable importance of these three heavy metals (figure 2) time after acidification and current density are varied in the plot, while the remaining experimental variables are set at fixed levels. Figure 5

The contour plots are valuable tools for developing a remediation strategy to meet remediation goals. The contour plots indicate the experimental domain to operate within, in order to achieve specific remediation objectives. The most site-appropriate strategy can then be chosen according to whether time or energy consumption is considered more vital.

To meet the Norwegian background levels, the simultaneous remediation of the three targeted heavy metals $\mathrm{Cu}, \mathrm{Pb}$ and $\mathrm{Zn}$ is necessary in this study. Instead of comparing the contour plots in figure 5, a 'sweet spot' plot was made - essentially three overlaying contour plots (figure 6). As above the time after acidification and current density are varied, while the remaining experimental variables are fixed at constant values. The sweet spot plot illustrates the space in which one heavy metal, two heavy metals and all the heavy metals (sweet spot), respectively meet the specified remediation objectives. For the sediment in this study it would be necessary to operate 
at high levels of both current density and time after acidification to reach levels equivalent to Norwegian background levels.

Figure 6

\section{Conclusion}

Multivariate design and analysis revealed that the variables current density and remediation time had the highest influence on the removal of $\mathrm{Cr}, \mathrm{Cu}, \mathrm{Ni}, \mathrm{Pb}$ and $\mathrm{Zn}$. The PLS model was significantly improved by substituting remediation time with time after acidification, making it possible to determine optimal experimental settings for removing targeted heavy metals in specific sediment.

Since the PLS model revealed that the variables $L / S$ ratio, stirring rate, suspension liquid and light/no light had a lower influence on the EDR process for the specific sediment, these were kept fixed, while optimal settings for current density and time after acidification were determined. The study showed the potential of applying multivariate design and analysis as a tool for determining variable importance and optimal conditions.

\section{Acknowledgements}

Hammerfest municipality is acknowledged for providing boat for sampling of sediments in Hammerfest. The Northern Environmental Waste Management (EWMA) project, which is funded by the Research Council of Norway through NORDSATSNING (grant number 195160) and Eni Norge AS, is acknowledged for funding.

\section{References}

1. Environment Mo. Stortingsmelding 14(2006-2007) 10.2 Handlingsplan for opprydding i forurenset sjøbunn. In: Environment Mo, editor.: The Norwegian Parliament; 2007. 
2. Carlson R, Carlson JE. Design and Optimisation in Organic Synthesis. Second ed: Elsevier; 2005.

3. Wold S, Sjöström M, Eriksson L. PLS-regression: a basic tool of chemometrics. Chemometrics and Intelligent Laboratory Systems. 2001;58(2):109-30. doi: http://dx.doi.org/10.1016/S0169-7439(01)00155-1.

4. Trygg J, Wold S. Orthogonal projections to latent structures (O-PLS). Journal of Chemometrics. 2002;16(3):119-28. doi: 10.1002/cem.695.

5. Abdi H. Partial least squares regression and projection on latent structure regression (PLS Regression). Wiley Interdisciplinary Reviews: Computational Statistics. 2010;2(1):97-106. doi: 10.1002/wics.51.

6. Ottosen LM, Nystrom GM, Jensen PE, Villumsen A. Electrodialytic extraction of $\mathrm{Cd}$ and $\mathrm{Cu}$ from sediment from Sisimiut Harbour, Greenland. J Hazard Mater. 2007;140(1-2):271-9. doi: DOI 10.1016/j.jhazmat.2006.08.002. PubMed PMID: ISI:000244362500032.

7. Nystroem GM, Ottosen LM, Villumsen A. Acidification of harbor sediment and removal of heavy metals induced by water splitting in electrodialytic remediation. Separ Sci Technol. 2005;40(11):2245-64. doi: Doi 10.1080/01496390500201367. PubMed PMID: ISI:000231954200005.

8. Nystroem GM, Ottosen LM, Villumsen A. Electrodialytic removal of Cu, Zn, $\mathrm{Pb}$, and $\mathrm{Cd}$ from harbor sediment: Influence of changing experimental conditions. Environ Sci Technol. 2005;39(8):2906-11. doi: Doi 10.1021/Es048930w. PubMed PMID: ISI:000228428900069.

9. Kirkelund GM, Ottosen LM, Villumsen A. Investigations of $\mathrm{Cu}, \mathrm{Pb}$ and $\mathrm{Zn}$ partitioning by sequential extraction in harbour sediments after electrodialytic remediation. Chemosphere. 2010;79(10):997-1002. doi: DOI 10.1016/j.chemosphere.2010.03.015. PubMed PMID: ISI:000278161600003. 10. Kirkelund GM, Ottosen LM, Villumsen A. Electrodialytic remediation of harbour sediment in suspension-Evaluation of effects induced by changes in stirring velocity and current density on heavy metal removal and $\mathrm{pH}$. J Hazard Mater. 2009;169(1-3):685-90. doi: DOI 10.1016/j.jhazmat.2009.03.149. PubMed PMID: ISI:000268967200094.

11. Nystroem GM, Pedersen AJ, Ottosen LM, Villumsen A. The use of desorbing agents in electrodialytic remediation of harbour sediment. Sci Total Environ. 2006;357(1-3):25-37. doi: DOI 10.1016/j.scitotenv.2005.04.040. PubMed PMID: ISI:000236190400003.

12. Nystrom GM, Ottosen LM, Villumsen A. Test of experimental set-ups for electrodialytic removal of $\mathrm{Cu}, \mathrm{Zn}, \mathrm{Pb}$ and $\mathrm{Cd}$ from different contaminated harbour sediments. Eng Geol. 2005;77(3-4):349-57. doi: DOI 10.1016/j.enggeo.2004.07.025. PubMed PMID: ISI:000228023000017.

13. Nystrom GM, Ottosen LM, Villumsen A. The use of sequential extraction to evaluate the remediation potential of heavy metals from contaminated harbour sediment. J Phys Iv. 2003;107:975-8. doi: Doi 10.1051/Jp4:20030461. PubMed PMID: ISI:000183782500059.

14. Acar YB, Alshawabkeh AN. Principles of Electrokinetic Remediation. Environ Sci Technol. 1993;27(13):2638-+. PubMed PMID: ISI:A1993MJ95600007.

15. Acar YB, Gale RJ, Alshawabkeh AN, Marks RE, Puppala S, Bricka M, et al. Electrokinetic Remediation - Basics and Technology Status. J Hazard Mater. 1995;40(2):117-37. PubMed PMID: ISI:A1995QF62500002. 
16. Alshawabkeh AN. Electrokinetic Soil Remediation: Challenges and

Opportunities. Separ Sci Technol. 2009;44(10):2171-87. doi: Doi

10.1080/01496390902976681

Pii 913162449. PubMed PMID: ISI:000269792700002.

17. Hansen HK, Ottosen LM, Laursen S, Villumsen A. Electrochemical analysis of ion-exchange membranes with respect to a possible use in electrodialytic decontamination of soil polluted with heavy metals. Separ Sci Technol. 1997;32(15):2425-44. PubMed PMID: ISI:A1997YD48900002.

18. Jensen PE, Ottosen LM, Ferreira C, Villumsen A. Kinetics of electrodialytic extraction of $\mathrm{Pb}$ and soil cations from a slurry of contaminated soil fines. J Hazard Mater. 2006;138(3):493-9. doi: DOI 10.1016/j.jhazmat.2006.05.073. PubMed PMID: ISI:000242327400010.

19. Rajic LM, Dalmacija BD, Trickovic JS, Dalmacija MB, Krcmar DM. Behavior of zinc, nickel, copper and cadmium during the electrokinetic remediation of sediment from the Great Backa Canal (Serbia). Journal of Environmental Science and Health, Part A. 2010;45(9):1134-43. doi: 10.1080/10934529.2010.486347.

20. Rajić L, Dalmacija B, Perović SU, Pešić V, Dalmacija M, Klašnja M, et al. Improving the Electrokinetic Remediation of Nickel-, Cadmium-, and Leadcontaminated Sediment. Soil and Sediment Contamination: An International Journal. 2012;22(2):199-207. doi: 10.1080/15320383.2013.722135.

21. Kim K-J, Kim D-H, Yoo J-C, Baek K. Electrokinetic extraction of heavy metals from dredged marine sediment. Sep Purif Technol. 2011;79(2):164-9. doi:

http://dx.doi.org/10.1016/j.seppur.2011.02.010.

22. Colacicco A, De Gioannis G, Muntoni A, Pettinao E, Polettini A, Pomi R. Enhanced electrokinetic treatment of marine sediments contaminated by heavy metals and PAHs. Chemosphere. 2010;81(1):46-56. doi:

http://dx.doi.org/10.1016/j.chemosphere.2010.07.004.

23. Rauret G, Lopez-Sanchez JF, Sahuquillo A, Rubio R, Davidson C, Quevauviller

P. Improvement of the BCR three step sequential extraction procedure prior to the certification of new sediment and soil reference materials. J Environ Monitor. 1999;1:57-61.

24. Nystroem GM. Electrodialytic removal of heavy metals from contaminated harbour sediments. Lyngby: DTU; 2004.

Table 1. The experimental designs.

\begin{tabular}{|c|c|c|c|c|c|c|}
\hline Exp. & Time & $\begin{array}{l}\text { Current } \\
\text { density }\end{array}$ & L/S & $\begin{array}{l}\text { Stirring } \\
\text { rate }\end{array}$ & Light & $\begin{array}{l}\text { Suspension } \\
\text { liquid }\end{array}$ \\
\hline & (h) & $\left(\mathrm{mA} / \mathrm{cm}^{2}\right)$ & $(\mathrm{ml} / \mathrm{g})$ & (rpm) & - & - \\
\hline \multicolumn{7}{|c|}{ Design 1} \\
\hline 1 & 192 & 0.04 & 2 & 1300 & Yes & Tap water \\
\hline 2 & 672 & 0.04 & 2 & 1 & No & Tap water \\
\hline 3 & 192 & 0.80 & 2 & 1 & Yes & Dist. water \\
\hline 4 & 672 & 0.80 & 2 & 1300 & No & Dist. water \\
\hline 5 & 192 & 0.04 & 12 & 1300 & No & Dist. water \\
\hline 6 & 672 & 0.04 & 12 & 1 & Yes & Dist. water \\
\hline 7 & 192 & 0.80 & 12 & 1 & No & Tap water \\
\hline 8 & 672 & 0.80 & 12 & 1300 & Yes & Tap water \\
\hline 9 & 432 & 0.42 & 7 & 650 & Yes & Dist. water \\
\hline
\end{tabular}




\begin{tabular}{|l|l|l|l|l|l|l|}
\hline 10 & 432 & 0.42 & 7 & 650 & Yes & Dist. water \\
\hline 11 & 432 & 0.42 & 7 & 650 & No & Dist. water \\
\hline 12 & 432 & 0.42 & 7 & 650 & No & Dist. water \\
\hline \multicolumn{7}{|l|}{ Design 2} \\
\hline 13 & $142^{*}$ & 0.80 & 2 & 1300 & Yes & Dist. water \\
\hline 14 & $2 *$ & 0.04 & 2 & 1300 & Yes & Dist. water \\
\hline 15 & $72 *$ & 0.42 & 2 & 1300 & Yes & Dist. water \\
\hline
\end{tabular}

*time after acidification

Figure 1. Model summaries of model 1a, model 1b and model 2: a). Model summary plot of all models (including all the metals) b).-d). Model summary plots of modelling each metal individually in models $1 \mathrm{a}, 1 \mathrm{~b}$ and 3.

Figure 2. VIP Plots of Model 2. a) All the metals combined (one model); b). Individual modelling - mobile trace elements in soil; c). Individual modelling - sediment trace elements; d). Individual modelling - contaminants in the sediment.

Figure 3. The maximum removal of metals (\%) in the experimental domain of the 15 electrodialytic experiments, compared to the exchangeable, reducible, oxidisable and residual fractions (\%) in the sediment determined by sequential extraction. 
Figure 4. Initial and lowest final contaminant concentration levels in the experimental domain compared to background values defined by OSPAR and the Norwegian EPA.

Figure 5. Removal efficiency (\%) of a) $\mathrm{Cu}, \mathrm{b}) \mathrm{Pb}$ and c) $\mathrm{Zn}$ as a function of time after acidification and current density (model 2). The remaining experimental variables were fixed at: stirring rate of $650 \mathrm{rpm}$; liquid-solid ratio of $7 \mathrm{mg} / \mathrm{ml}$, suspension liquid distilled water and light.

Figure 6. Sweet spot of remediation to obtain concentrations of contaminants equivalent to background values as determined by the Norwegian EPA, i.e. Cu removal efficiency of min. $40 \%$; Pb removal efficiency of min. 66\% and $\mathrm{Zn}$ removal efficiency of min. $31 \%$. In the plot the stirring rate was constant at $650 \mathrm{rpm}$, liquid-solid ratio was $7 \mathrm{mg} / \mathrm{ml}$ and suspension liquid was distilled water. 


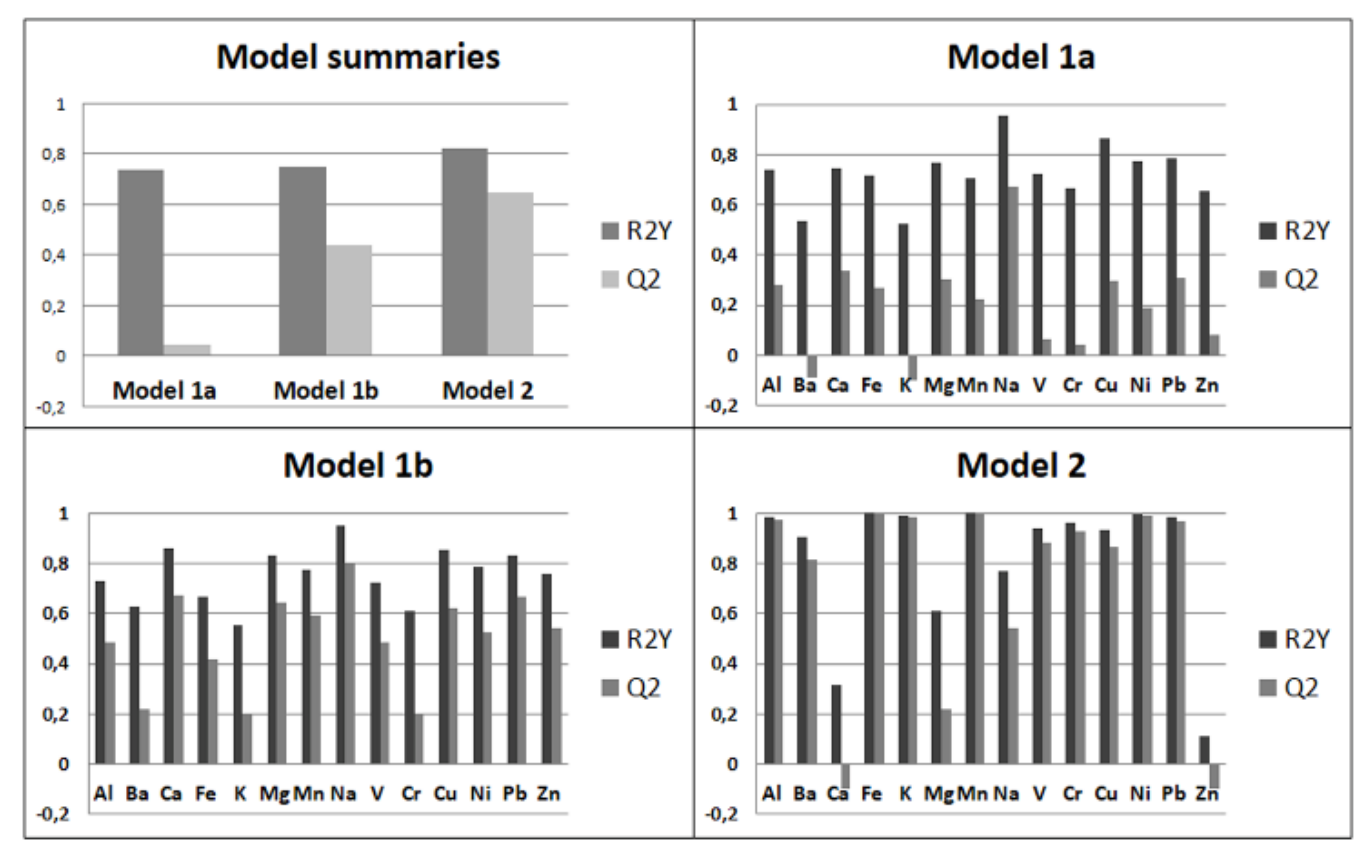

Figure 1 


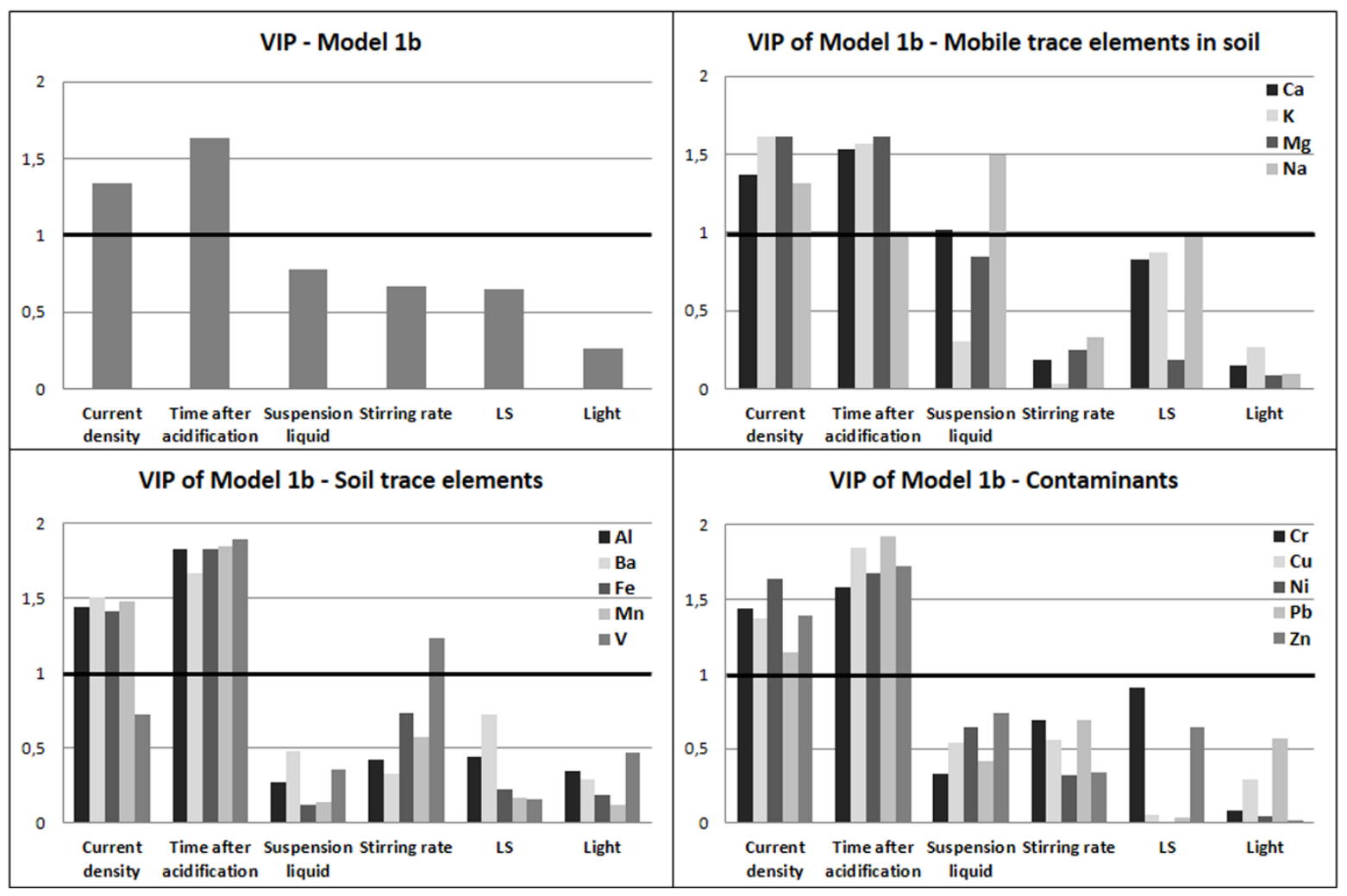

Figure 2 


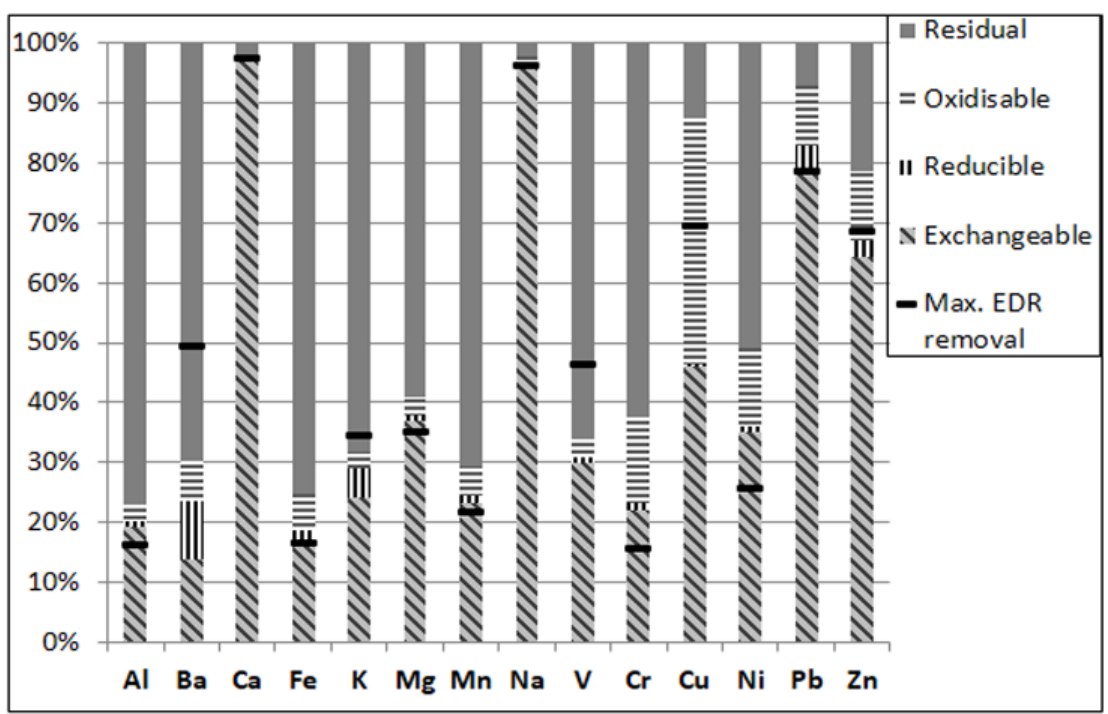

Figure 3 


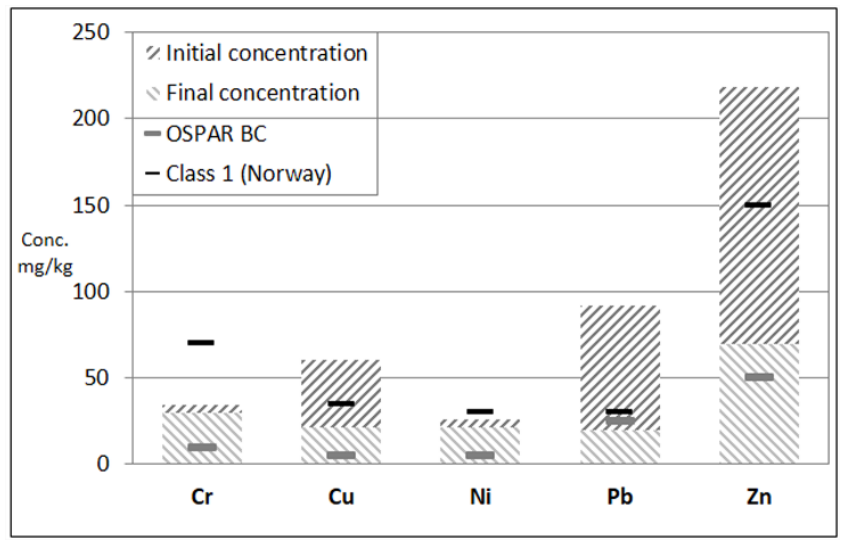

Figure 4 


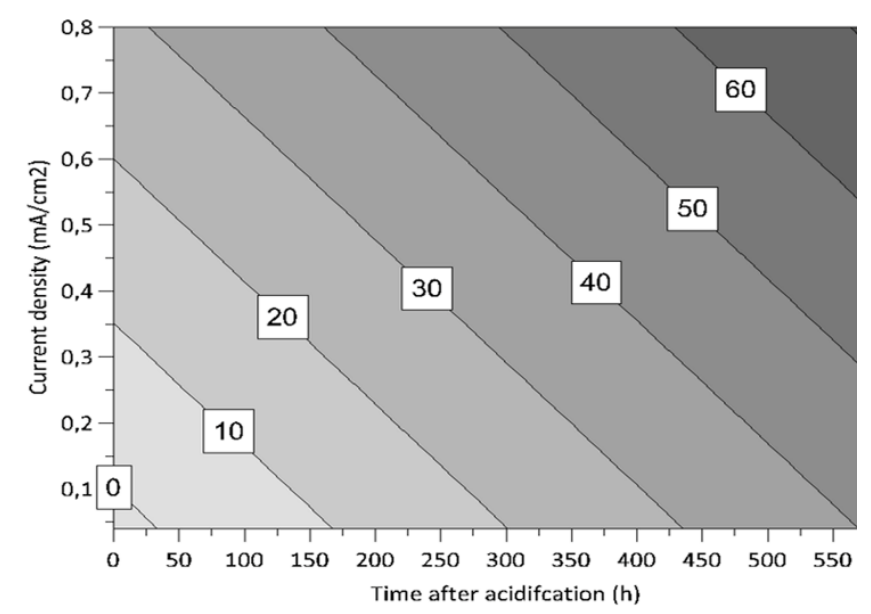

Figure 5a

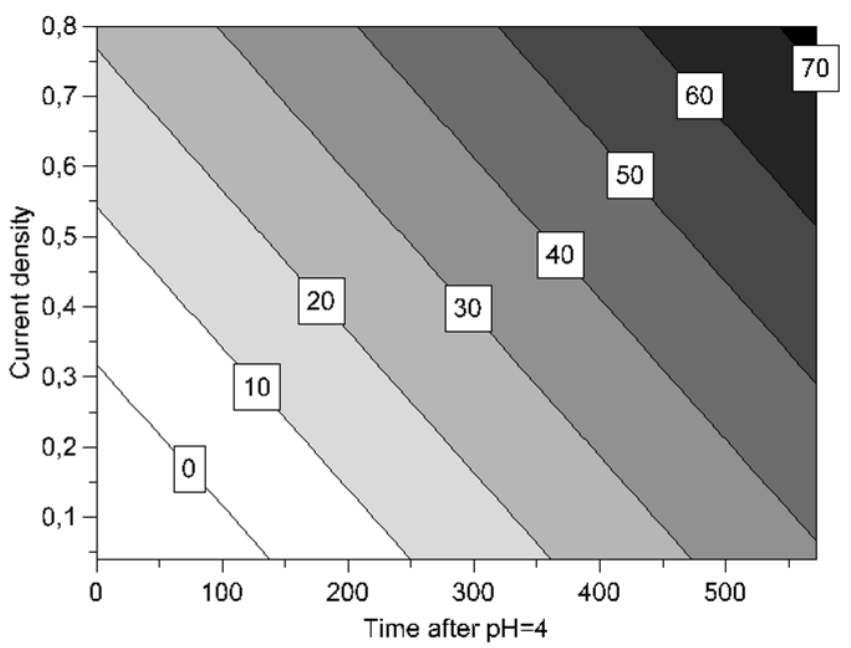

Figure 5b

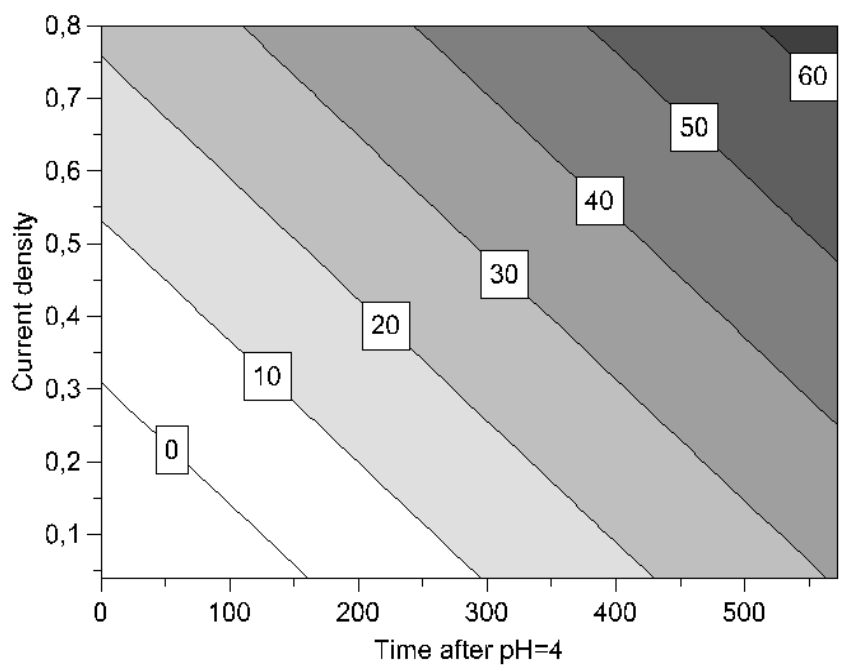

Figure 5c 


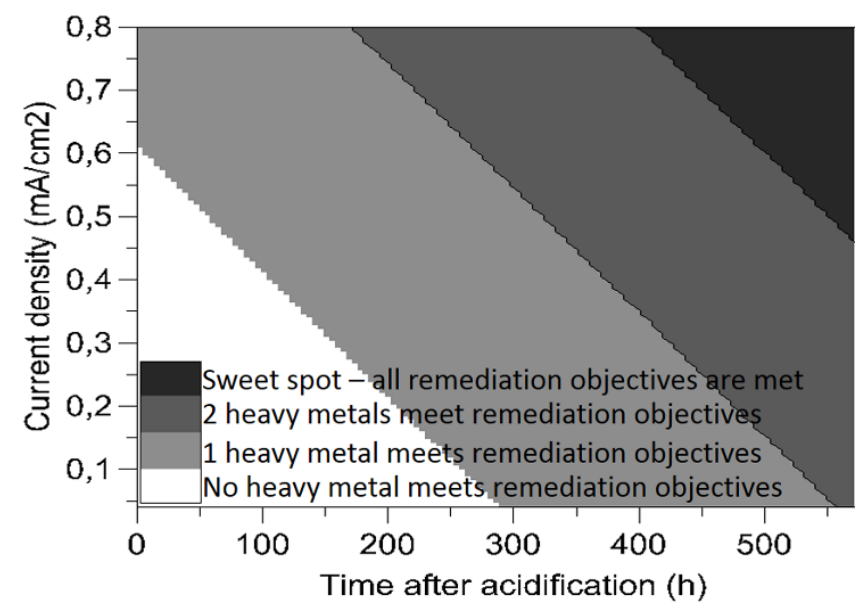

Figure 6 